\title{
ANATOMIA DA MADEIRA DE DUAS BIGNONIÁCEAS DA FLORESTA ESTACIONAL DE MISIONES - ARGENTINA ${ }^{1}$
}

\author{
GRACIELA INES BOLZON DE MUÑIZ ${ }^{2}$ JOSÉ NEWTON CARDOSO MARCHIORI ${ }^{3}$
}

\section{RESUMO}

São anatomicamente descritas e ilustradas as madeiras de Jacaranda micrantha Cham. e Handroanthus albus (Cham.) Mattos, com base em material procedente de Misiones, Argentina.

Palavras-chave: Jacaranda micrantha, Handroanthus albus, Bignoniaceae, anatomia da madeira.

\section{SUMMARY}

[Wood anatomy of two Bignoniaceous species from Misiones Seasonal Forest - Argentina].

The woods of Jacaranda micrantha Cham. and Handroanthus albus (Cham.) Mattos are anatomically described and illustrated, based on materials from Misiones province, Argentina.

Key words: Jacaranda micrantha, Handroanthus albus, Bignoniaceae, wood anatomy.

\section{INTRODUÇÃO}

O presente estudo trata da descrição anatômica da madeira de duas Bignoniáceas euxilóforas da Floresta Estacional de Misiones: Jacaranda micrantha Cham., a popular caroba, e Handroanthus albus (Cham.) Mattos, conhecido como lapacho-amarillo, na Argentina (Dimitri et al., 2000), e ipê-amarelo, ipê-da-serra ou ipêvacariano, no Brasil (Sobral et al., 2006).

Nativa no leste do Paraguai, nordeste da Argentina (Misiones) e Brasil, de Minas Gerais ao Rio Grande do Sul (Gentry, 1992), Jacaranda micrantha é árvore de 10 - $25 \mathrm{~m}$ de altura, com fuste de 10 - $15 \mathrm{~m}$, e copa alongada. Muito parecida a Jacaranda puberula Cham., a espécie em foco difere, na mata, principalmente por seu maior tamanho e pelos frutos em forma de cáp-

1 Recebido em 20-2-2007 e aceito para publicação em 30-8-2007.

2 Engenheira Florestal, Dra., Professora Titular do Departamento de Engenharia e Tecnologia Florestal, Universidade Federal do Paraná. Curitiba (PR). CEP 80070.230. gbmunize@ufpr.br

3 Engenheiro Florestal, Dr., Professor Titular do Departamento de Ciências Florestais, Universidade Federal de Santa Maria. Santa Maria (RS). CEP 97105.900. balduinia@mail.ufsm.br sula orbicular, de bordo ondulado (Sandwith \& Hunt, 1974). Cabe salientar que a estrutura anatômica desta espécie de madeira foi anteriormente publicada como Tabebuia semisserrata Cham., por Tortorelli (1956).

Nativa da Argentina, Paraguai e Brasil, de Minas Gerais e Rio de Janeiro ao Rio Grande do Sul (Gentry, 1992), Handroanthus albus (Cham.) Mattos comumente figura na literatura botânica como Tabebuia alba (Cham.) Sandwith, binômio atualmente reduzido à sinonímia. Árvore de grande porte, com troncos de até $30 \mathrm{~m}$ de altura e 1,50 $\mathrm{m}$ de diâmetro, apresenta casca espessa castanho-acinzentada, com fissuras longitudinais. A madeira, muito pesada e de notável resistência, também mereceu descrição anatômica, por Tortorelli (1956).

\section{MATERIAL E MÉTODOS}

Para cada uma das espécies foram estudadas amostras de madeira de três árvores, procedentes de uma floresta natural da Universidad Nacional de Misiones (departamento de Guarani, Argentina). Extraído em região de alburno e à altura do peito, o material lenhoso foi incorporado ao acervo do Laboratório de Dendrología, da Facultad de Ciencias Forestales da mesma universidade. 
De cada indivíduo foram preparados três corpos-de-prova, orientados para a obtenção de cortes anatômicos nos planos transversal, longitudinal radial e longitudinal tangencial. Após amolecimento por fervura em água, os corposde-prova foram seccionados em micrótomo de deslizamento (modelo Spencer AO n. 860), regulado para a obtenção de cortes com espessura nominal de $18 \mu \mathrm{m}$. Usou-se coloração com acridina-vermelha, crisoidina e azul-de-astra (Dujardin, 1964), desidratação em série alcoólica e montagem permenente com "Entellan".

No preparo de lâminas de macerado seguiuse o método de Jeffrey (Freund, 1970), usandose coloração da pasta de fibras com safranina e o mesmo meio-de-montagem anteriormente referido.

Os dados quantitativos da estrutura anatômica foram processados diretamente em analisador de imagens "Videoplan", acoplado a computador, obtendo-se os respectivos valores mínimos, médios, máximos e desvio padrão (s), com o uso de programas aplicativos.

A descrição de elementos macroscópicos baseou-se na Copant (1973). As mensurações de elementos celulares individuais e descrições microscópicas seguiram Ibama (1992). As fotomicrografias foram tomadas em aparelho Carl Zeiss, usando-se filme Kodak Panatomic X ASA 32 e ampliações em papel fotográfico Kodabromid F-3 brilhante.

\section{DESCRIÇÃO DAS MADEIRAS \\ 1 - Jacaranda micrantha Cham.}

Caracteres gerais: madeira leve a moderadamente pesada $\left(0,61 \mathrm{~g} / \mathrm{cm}^{3}\right)$, de cerne e alburno indistintos e cor branco-palha, levemente rosada, com delicadas estrias longitudinais mais escuras. Sem odor e gosto característicos, com figura demarcada pela disposição dos poros e tecido fibroso, apresenta brilho suave, textura média heterogênea e grã direita a irregular.

Anéis de crescimento: quase sempre distintos, individualizados pela variação na espessura da parede de fibras entre os lenhos tardio e inicial, bem como pelo parênquima axial mar- ginal terminal, em faixas interrompidas (Figura 1A, B).

Vasos: arredondados $(74-84-104 \mu \mathrm{m} ; \mathrm{s}=$ 30,09 ), em porosidade difusa e com paredes medianamente espessas (cerca de $3 \mu \mathrm{m}$ ); predominantemente solitários, em múltiplos radiais de 2 a 5 e em escassos cachos (Figura 1A, B). Elementos vasculares de $179-250-329$ $\mu \mathrm{m}$ de comprimento $(\mathrm{s}=32,89)$, com placas de perfuração simples. Pontoações intervasculares alternas (Figura 1D), circulares $(3,5-6-8,5$ $\mu \mathrm{m} ; \mathrm{s}=0,76)$, com aberturas horizontais, inclusas, por vezes coalescentes. Pontoações raiovasculares e parênquimo-vasculares, semelhantes às intervasculares.

Parênquima axial: paratraqueal escasso e confluente em faixas interrompidas de $1-4$ células de espessura. Células parenquimáticas em séries de 2 a 4, com cerca de $60 \mu \mathrm{m}$ de altura e $30 \mu \mathrm{m}$ de largura.

Raios: heterogêneos, não estratificados (Figura 1D), com frequiência de $8-9-11$ por $\mathrm{mm}$ e $97-171-349 \mu \mathrm{m}$ de altura $(\mathrm{s}=47,78)$. Raios unisseriados, principalmente de células quadradas e eretas; os multisseriados (bi a tetrasseriados), com células procumbentes, na parte central, e células quadradas e eretas nas margens (Figura 1C). Raios fusionados, freqüentes.

Fibras: libriformes, não septadas e de seção poligonal, com pontoações simples ou inconspicuamente areoladas nas faces radiais da parede; medem 616 - $900-1125 \mu \mathrm{m}$ de comprimento $(\mathrm{s}=99,00)$ e $12-15-23 \mu \mathrm{m}$ de diâmetro.

Outros caracteres: canais intercelulares, canais celulares, cistos glandulares, estruturas estratificadas, floema incluso, células oleíferas, células mucilaginosas e máculas medulares, ausentes. Cristais e sílica, não observados.

\section{2 - Handroanthus albus (Cham.) Mattos}

Caracteres gerais: madeira com massa específica de 0,80 a $1,00 \mathrm{~g} / \mathrm{cm}^{3}$, de alburno brancorosado e cerne rosa, sem odor e gosto distintos, de textura média, grã irregular a revessa, com superfície lisa ao tato, irregularmente lustrosa e 

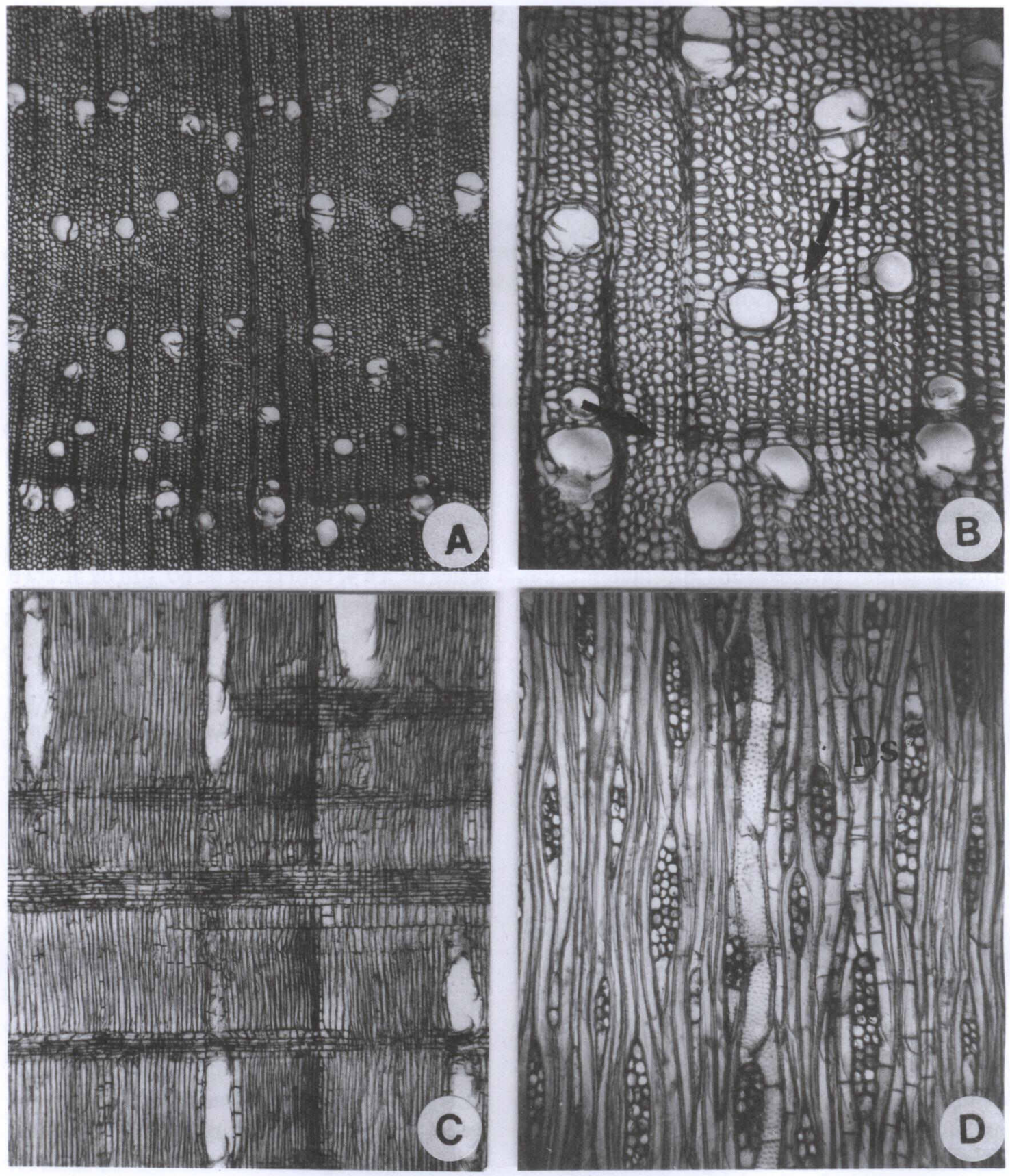

FIGURA 1 - Aspectos anatômicos da madeira de Jacaranda micrantha. A - Seção transversal, mostrando limite de anel de crescimento e porosidade difusa, com vasos solitários e em múltiplos radiais de poucas unidades. B - Mesmo plano anatômico, destacando um limite de anel de crescimento (seta), poros solitários e em múltiplos radiais de poucas unidades, e parênquima paratraqueal (p) escasso a confluente, em estreitas faixas interrompidas, de 1 - 4 células de espessura. $\mathrm{C}$ - Tecido radial heterogêneo, em seção longitudinal radial. D - Seção longitudinal tangencial, mostrando raios uni e multisseriados, não estratificados, parênquima seriado (Ps) e elementos vasculares com pontoações intervasculares alternas. Escala $=125 \mu \mathrm{m}(\mathrm{A}, \mathrm{C}) ; 40$ $\mu \mathrm{m}$ (B, D). 

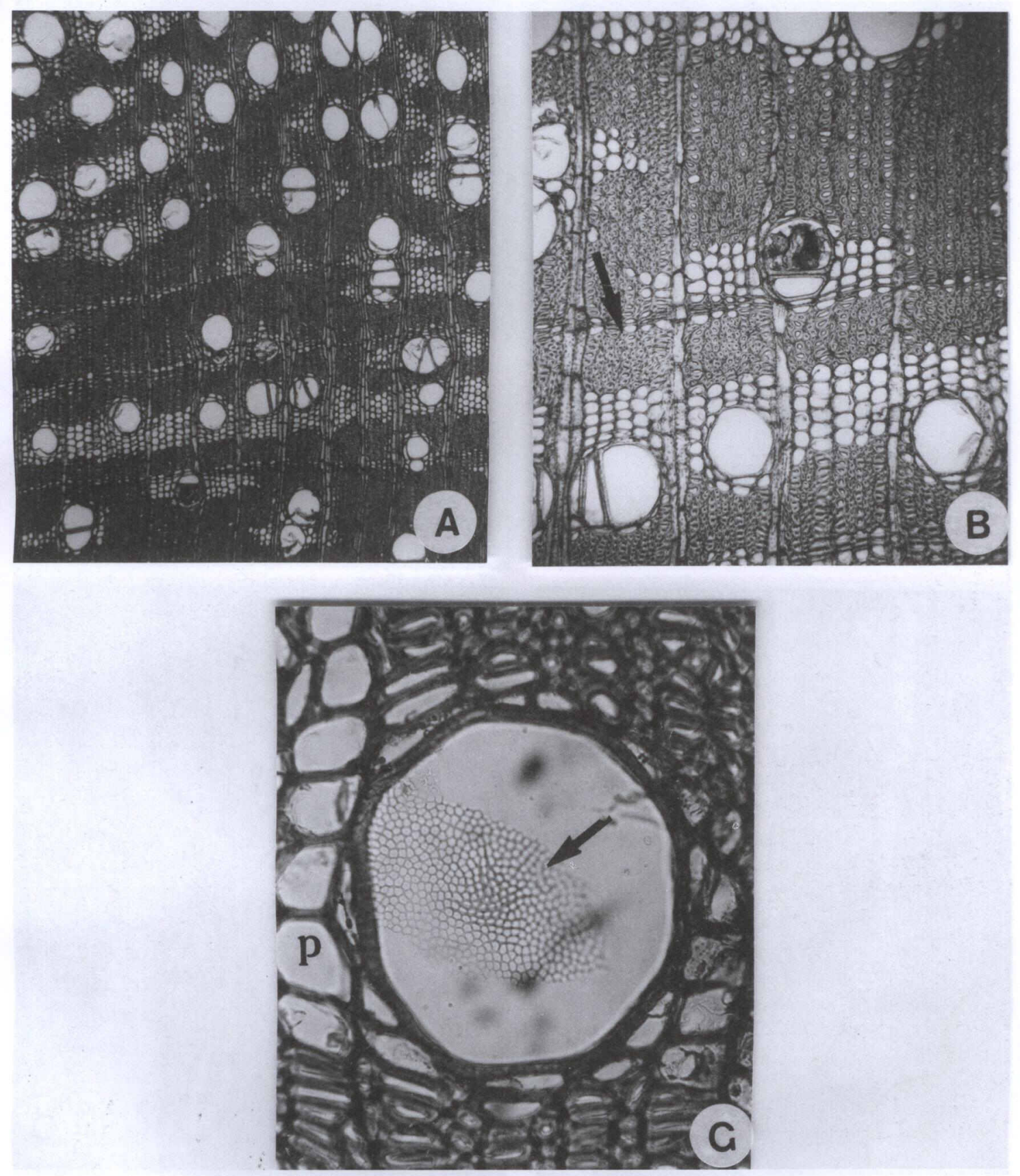

FIGURA 2 - Aspectos anatômicos da madeira de Handroanthus albus, em seção transversal. A-Porosidade difusa, com vasos arredondados, em sua maioria solitários, menos comumente em múltiplos radiais de 2 - 3 e escassos cachos, e parênquima paratraqueal vasicêntrico, tendente a aliforme e aliforme-confluente. B - Vasos solitários, geminados, e parênquima axial aliforme, aliforme-confluente e em estreita faixa terminal (seta). C - Vista parcial de placa de perfuração reticulada (seta). Escala $=125 \mu \mathrm{m}$ (A); $40 \mu \mathrm{m}$ (B); 12,5 $\mu \mathrm{m}(\mathrm{C})$. 

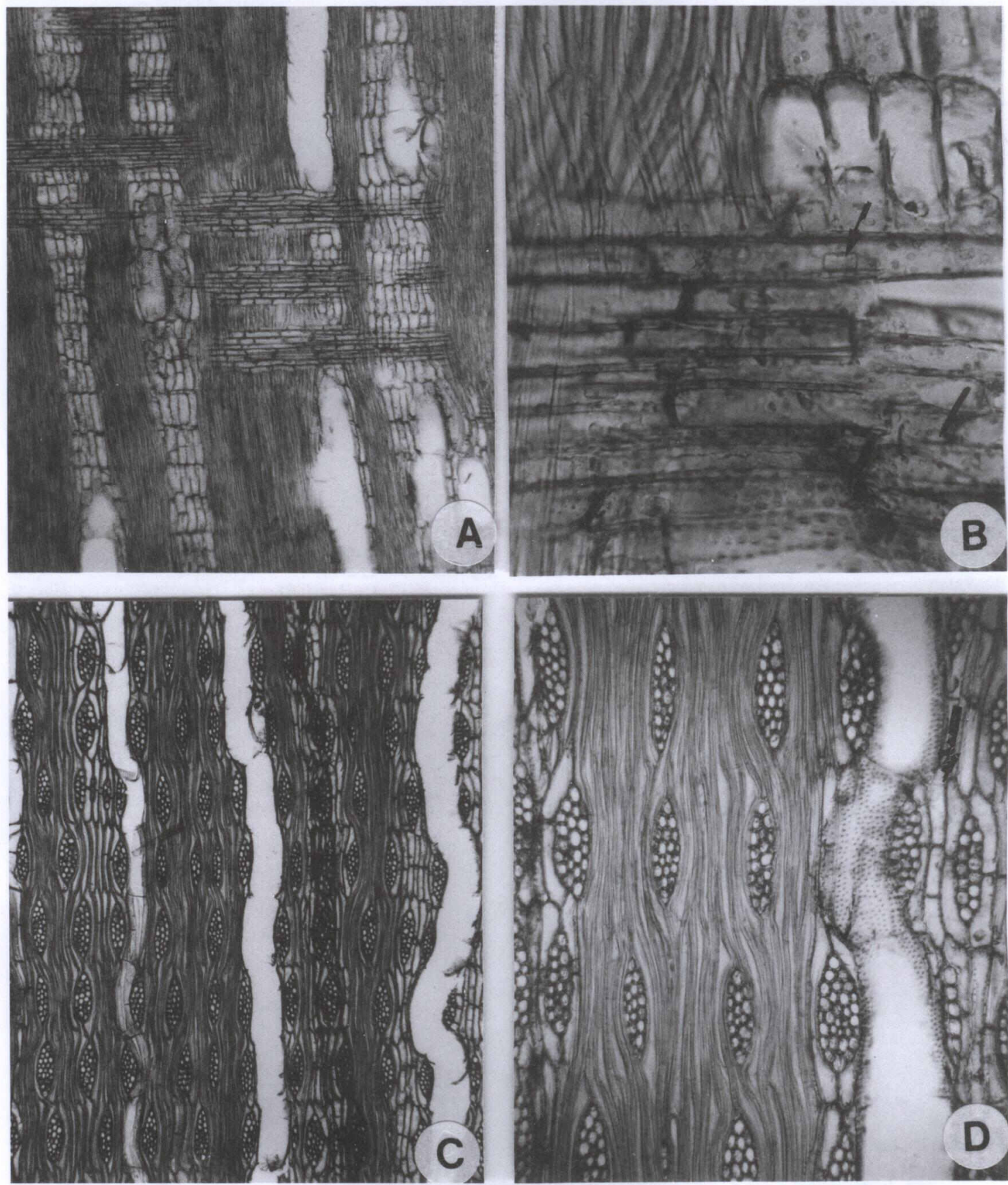

FIGURA 3 - Aspectos anatômicos da madeira de Handroanthus albus, em seções longitudinais. A - Tecido radial homogêneo, composto inteiramente de células procumbentes, e parênquima axial estratificado (seção radial). B - Raio homogêneo, com cristais de oxalato de cálcio em células procumbentes, e pontoações raiovasculares (seção radial). C - Estratificação de todos os elementos celulares, vista em seção tangencial. D - Parênquima axial com 2 - 3 células por série, organizado em estratos, juntamente com raios multisseriados (seção tangencial). Escala $=125 \mu \mathrm{m}(\mathrm{A}, \mathrm{C}) ; 40 \mu \mathrm{m}(\mathrm{D}) ; 12,5 \mu \mathrm{m}(\mathrm{B})$. 
de aspecto fibroso; notável por sua alta durabilidade, mesmo exposta às intempéries.

Anéis de crescimento: pouco demarcados, reconhecidos por estreitas linhas de parênquima marginal (Figura 2B).

Vasos: em porosidade difusa, com freqüência de 6-14-17 poros $/ \mathrm{mm}^{2}(\mathrm{~s}=2,98)$; solitários, em múltiplos radiais de 2 a 3 e em escassos cachos (Figura 2A,B). Vasos arredondados $(58-100-158 \mu \mathrm{m} ; \mathrm{s}=27,65)$, com paredes de $5 \mu \mathrm{m}$ de espessura média (Figura 2A, B). Elementos vasculares estratificados (Figura 3C), de $200-240-280 \mu \mathrm{m}$ de comprimento ( $\mathrm{s}=$ 20,78), com placas de perfuração simples, horizontais ou levemente inclinadas; placas reticuladas, raras (Figura 2C). Pontoações intervasculares alternas, circulares $(2,5-7 \mu \mathrm{m})$, com abertura lenticular, inclusa. Pontoações raio-vasculares (Figura $3 \mathrm{~B}$ ) e parênquimovasculares, muito pequenas, semelhantes às intervasculares.

Parênquima axial: paratraqueal vasicêntrico, por vezes incompleto, com certa tendência a unilateral, aliforme e aliforme-confluente (Figura 2A, B); também em faixa terminal estreita (Figura 2B). Séries parenquimáticas de 200 $240-260 \mu \mathrm{m}$ de altura $(\mathrm{s}=24,32)$, compostas de 2, raro 3 células (Figura 3D). Cristais de oxalato de cálcio pequenos, prismáticos, fusiformes e aciculares, presentes na maioria das células. Parênquima estratificado, acompanhando a estratificação de vasos e raios (Figura 3C, D).

Raios: homogêneos, compostos inteiramente de células procumbentes (Figura 3A, B) e com freqüência de 5- 7 - 11 raios $/ \mathrm{mm}$; são geralmente trisseriados, com menor freqüência bisseriados e tetrasseriados, havendo poucos 5seriados e raros unisseriados. Raios estratificados (Figura 3C, D), de $70-210 \mu \mathrm{m}$ de altura, raro fusionados, correspondendo à altura de 2 estratos. Cristais de oxalato de cálcio semelhantes aos do parênquima axial, abundantes (Figura 3B).

Fibras: libriformes, com pontoações simples ou inconspicuamente areoladas; medem 690 800 - $900 \mu \mathrm{m}$ de comprimento $(\mathrm{s}=112,31) \mathrm{e}$
$17-21-28 \mu \mathrm{m}$ de diâmetro $(\mathrm{s}=2,31)$.

Outros caracteres: Canais intercelulares, canais celulares, cistos glandulares, floema incluso, células oleíferas, células mucilaginosas e máculas medulares, ausentes.

\section{ANÁLISE DA ESTRUTURA ANATÔMICA}

As duas espécies em estudo são facilmente separadas mediante estudo da estrutura anatômica. Handroanthus albus distingue-se, prontamente, pela estrutura estratificada completa, pelos raios homocelulares e pelas fibras de paredes espessas, contrastantes com o parênquima axial em corte transversal. Jacaranda micrantha, por sua vez, carece de estratificação, apresenta raios heterogêneos e suas fibras, de paredes relativamente finas, pouco contrastam com o parênquima axial em plano transversal.

\section{REFERÊNCIAS BIBLIOGRÁFICAS}

COPANT (Comissão Panamericana de Normas Técnicas). Descrição macroscópica, microscópica e geral da madeira - esquema I de recomendação. Colômbia, n. 30, p. 1-19, 1973.

DIMITRI, M.J.; LEONARDIS, R.F.J.; BILONI, J.S. El nuevo libro del arbol. Buenos Aires: El Ateneo, 2000. 124 p.

DUJARDIN, E.P. Eine neue Holz-Zellulosenfaerbung. Mikrokosmos, n. 53, p. 94, 1964.

FREUND, H. Handbuch derMikroskopie in der Technik. Frankfurt: Umsham Verlag, 1970.375 p.

IBAMA (Instituto Brasileiro do Meio Ambiente e dos Recursos Naturais Renováveis). Normas e procedimentos em estudos de Anatomia da Madeira. Brasília, 1992.17 p. (Ser. Técn. n. 15).

MATTOS, J.R. Handroanthus, um novo gênero para os "ipês" do Brasil. Loefgrenia, São Paulo, n. 50, p. 1-4, 1970.

SANDWITH, N.Y.; HUNT, D.R. Bignoniáceas. In : REITZ, P.R. Flora Ilustrada Catarinense. Itajaí: Herbário Barbosa Rodrigues, 1974. 172 p.

SOBRAL, M.; JARENKOW, J.A.; BRACK, P.; IRGANG, B.; LAROCCA, J.; RODRIGUES, R.S. Flora arbórea e arborescente do Rio Grande do Sul, Brasil. São Carlos: RiMA: Novo Ambiente, 2006. 350 p.

TORTORELLI, L.A. Maderas y bosques argentinos. Buenos Aires: ACME, 1956. 910 p. 